\title{
Gradient Symbolic Representations and the Typology of Ghost Segments
}

\author{
Eva Zimmermann \\ Universität Leipzig
}

\section{Introduction}

Ghost segments are best analysed as weakly active elements under the assumption of Gradient Symbolic Representations (Smolensky \& Goldrick, 2016; Rosen, 2016). This assumption allows to predict the attested interactions between phonological markedness constraints and the (non)appearance of ghost segments we find in the languages of the world: first, the co-existence of different types of ghost segments that differ in whether they appear to resolve a markedness problem or whether they disappear to avoid a markedness problem, and, second, the weak contribution to markedness of ghosts. The assumption that all underlying phonological elements have a certain activation that can gradiently differ and might persist into the output structure predicts these two phenomena straightforwardly that are challenging under alternative accounts to ghost segments. This paper is structured as follows: in 2.1, the phenomenon of phonologically conditioned ghost segments is introduced and the two types of appearing and disappearing ghost segments are identified. Subsections 2.2 and 2.3 focus on two case studies of ghost segments in Welsh and Ahousaht Nuu-chahnulth that illustrate the empirical arguments for the proposed account: Welsh employs both appearing and disappearing ghost segments with different markedness thresholds and Ahousaht Nuu-chah-nulth has ghost segments that only gradiently contribute to markedness. Section 3 then shows how the assumption of Gradient Symbolic Representations can easily account for these two phenomena. That alternatives based on autosegmental defectivity cannot easily predict them is discussed in section 4 . Section 5 concludes.

\section{Data: Ghost Segments and Markedness}

2.1 Appearing and disappearing ghost segments Ghost segments (='ghosts' $)^{1}$ are defined as segments that 1) are idiosyncratically bound to specific morphemes and 2) alternate with zero in a way that the majority of segments within this language do not. The first criterion is important since it distinguishes ghosts from epenthetic segments. In Ahousaht Nuu-chah-nulth (Kim, 2003), for example, several suffixes begin with a consonant that only surfaces if it is preceded by a vowel but not otherwise (e.g. / $\mathbf{k}_{\AA}$ ta:/ 'to

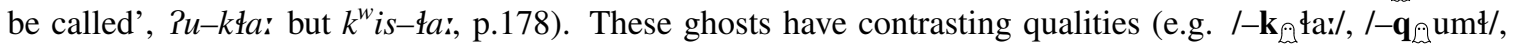
$/-\mathbf{y}_{\curvearrowleft} \mathrm{a} /$; p.178), they thus have to be part of the underlying representation of morphemes. Although their appearance is phonologically predictable, there is no general phonological process that would explain their alternation with zero. There is thus no general deletion applying to two-consonantal sequences preceded by another consonant in Ahousaht Nuu-chah-nulth (e.g. /nup-q?itf// 'one year', nupq. Ritfh, p.178). This illustrates the second property of ghosts, namely that they behave phonologically exceptional. Since this paper is focusses on the interaction between markedness constraints and ghosts, it will disregard instances where the realization of a ghost is apparently lexically determined. ${ }^{2}$ Within the markedness-determined ghosts, two crucially different types can be identified: those that solve a markedness problem and those that don't create a new markedness problem. Though this distinction seems subtle and a classification into one of these types is not always surface-apparent, their theoretical account is systematically different. This point

\footnotetext{
* For their valuable feedback I would like to thank the audiences of mfm 2017, AMP 2018, and the workshop 'Inside Segments' at LSA 2019. I'm especially grateful to Daniel Gleim, Sören Tebay, and Jochen Trommer for helpful comments and discussion.

1 The most common names in the literature are 'ghost' (e.g. Archangeli, 1991) or 'latent' segments (e.g. Zoll, 1996).

2 An example can be found in Catalan where the masculine marker can be analyzed as a ghost segment /- $\mathbf{u}_{\AA} /$ that only surfaces if it avoids a marked structure or is adjacent to specific lexical items (Bonet et al., 2007).
}

(C) 2019 Eva Zimmermann

Proceedings of AMP 2018 
will be essential in an analysis for Welsh were it is argued that both types can coexist within one language. The first type of ghosts can be found in Yawelmani Yokuts (1) (Newman, 1932; Archangeli, 1991; Noske, 1985; Zoll, 1996; Hansson, 2005). Certain CV-suffixes surface with their final vowel only if they precede a consonant (1-b-i), not if a vowel precedes (1-b-ii). Other suffixes, on the other hand, always surface with their final vowel (1-a).

Ghost vowels in Yawelmani (Zoll, 1996:182+183)

\begin{tabular}{|c|c|c|c|c|c|}
\hline & & i. $\mathrm{C}_{-}$ & & ii. $V_{-}$ & \\
\hline a. /-ni/ & IND. & talap-ni & 'bow' & xata:-ni & 'food' \\
\hline b. $/-m i_{\mathfrak{A}} /$ & Precative & amic-mi & 'having approached' & pana-m & 'having arrived' \\
\hline
\end{tabular}

The precative suffix can thus be characterized as ending in a ghost $/ \mathrm{i}_{\Omega} /$ that only surfaces if it avoids a complex coda (*a.micm). This type of ghost can be described as 'appearing' since it is absent as long as it does not help to avoid a marked structure, cf. (3). Further examples for appearing ghosts are Slavic yers (Szypra, 1992; Yearley, 1995), Mohawk vowels (Rowicka, 1998), French liaison consonants (Tranel, 1996a,b), or Catalan masculine /u/ (Bonet et al., 2007). A second type of ghosts can also be illustrated with Yawelmani data. Certain suffixes (2-b) begin with consonants that only surface post-vocalically (2-b-i), not post-consonantally (2-b-ii). ${ }^{3}$ This deletion of a ghost consonant avoids an illicit syllable with two coda consonants (*ho.go:nh.nel), that are repaired in other contexts by vowel epenthesis (cf. the /i/ in (2-a-ii)).

Ghost consonants in Yawelmani (Archangeli, 1991:271)

\begin{tabular}{ll|ll} 
& & i. V__report' & ii. C__ffloat' \\
\hline a. /-wsel/ & 'reflexive/reciprocal consequent adjunctive' & doso-wsel & hogo:n-iwsel \\
b. /-h & doso-hnel $/$ & 'consequent passive adjunctive' & hogon-nel
\end{tabular}

The subtle difference to the ghost vowels in (1) is that the ghost consonants only disappear if they would create a complex coda. If the markedness consideration about complex codas is irrelevant, they surface. This second type of disappearing ghosts is defined in (4). Other examples for disappearing ghosts are English /a/n/ (Yang, 2004) or Nuu-chah-nulth consonants (Kim, 2003).

Appearing ghost segments surface if their appearance resolves a markedness problem; their default state is to be unrealized.

Disappearing ghost segments surface if their appearance does not cause a markedness problem; their default state is to be realized.

To further illustrate the subtle but crucial difference between appearing and disappearing ghosts, the tables (5)+(6) summarize the four relevant contexts for vocalic and consonantal ghosts in Yawelmani. For each context, the two options of realizing or not realizing (=gray background) the ghost segment are listed together with their interaction with the crucial markedness constraint $* \mathrm{CC}$ ] penalizing coda clusters. ${ }^{4}$ Two important asymmetries between appearing and disappearing ghosts are apparent: first, the default state in case the relevant markedness constraint is indecisive is the absence of the ghost for an appearing one (5-i-b) but the presence of a disappearing one (6-i-a). And second, whereas both avoid the creation of the marked structure, the appearing ghost avoids it via its presence (5-ii-a) and the disappearing one via its absence (6-ii-b).

(5) Yawelmani: Appearing ghosts; cf. (1)

\begin{tabular}{|c|c|c|c|c|}
\hline \multirow{2}{*}{ i. $V_{-}$} & \multicolumn{3}{|r|}{ 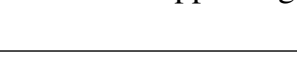 } & $* \mathrm{CC}]$ \\
\hline & & a. & pana-mi & Irrelevant \\
\hline & $\theta$ & b. & pana-m & Irrelevant \\
\hline ii. $\mathrm{C}_{-}$ & $\leftrightarrow \notin$ & a. & amic-mi & Avoided \\
\hline & & b. & amic-m & Created \\
\hline
\end{tabular}

(6) Yawelmani: Disappearing ghosts; cf. (2)

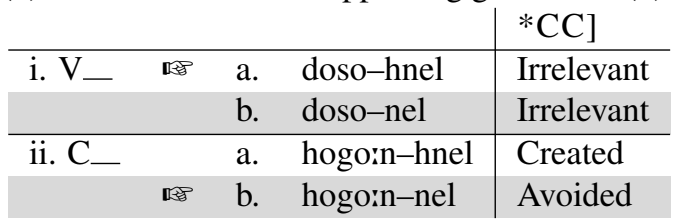

Given that the two illustrating examples for appearing and disappearing ghosts are from the same language, the Yawelmani pattern already poses a serious challenge for theoretical accounts that only allow for a binary

3 The different shapes of the base are due to the templatic morphology of Yawelmani (cf. Archangeli, 1984).

4 This is a simplification for *hogo:nnel since we expect epenthesis to avoid the coda cluster. That the expected marked structure is repaired by an independent process does not change the generalization about the default state for the ghost. 
distinction between ghosts and non-ghosts. As is discussed in more detail in section 4, such binary accounts can only establish a single default state for ghosts (being there or not) and the co-existence of appearing and disappearing ghosts is inherently problematic. For Yawelmani, a possible reanalysis might be based on the observation that the two types of ghosts involve different segment types. If the mechanism which sets the default state for ghosts can be sensitive to the distinction between vowels and consonants, this pattern can indeed follow. That such a solution is still insufficient for the typology of ghosts is shown in the next subsection where co-existing ghosts in Welsh are discussed. This pattern is more complex than the one in Yawelmani and crucially does not align the different types of ghosts with either vowels or consonants.

2.2 Appearing and disappearing ghosts in Welsh The first type of ghosts in Welsh (Hannahs \& Tallerman, 2006; Hannahs, 2013) can be found in some functional morphemes that end in a consonant which only surfaces if a vowel follows. This is shown for /gudag $\mathbf{g}_{\Omega} /$ 'with' in (7). These are taken to be appearing ghosts that only surface if they can avoid two adjacent vowels but remain unrealized otherwise.

Appearing ghost consonants in Welsh (Hannahs \& Tallerman, 2006:798+810)

\begin{tabular}{llll} 
i. __V & \multicolumn{3}{c}{ ii. _ C } \\
\hline $\begin{array}{lll}\text { gudag eraill } \\
\text { gudag un }\end{array}$ & 'with others' & guda gwên & 'with a smile' \\
guda tri & 'with three'
\end{tabular}

In addition, there is an intricate allomorphy for the definite article (8) where $/ \mathrm{yr} /{ }^{5}$ or different subsets of this string surface in phonologically predictable contexts. The full /yr/ surfaces before a vowel (8-a), only $/ \mathrm{y} /$ before a consonant (8-b), and only /'r/ after a vowel (8-c). These generalizations are reasonable from a perspective of markedness: (8-b) avoids an additional coda and (8-c) an additional vowel hiatus. It has to be noted that the last condition is always in conflict with the other two and overrides them: it is o'r llyfr, not *o y llyfr. The definite article is analysed here as two disappearing ghosts that surface as long as they don't create an additional coda or vowel hiatus. ${ }^{6}$

$$
\begin{aligned}
& \text { Disappearing ghosts in the Welsh definite allomorphy (Hannahs \& Tallerman, 2006:782+783) }
\end{aligned}
$$

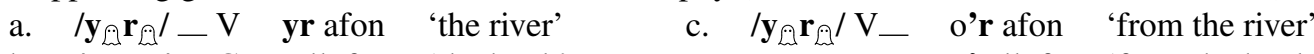

$$
\begin{aligned}
& \text { b. } \quad / \mathbf{y}_{\curvearrowleft} \mathbf{r}_{\curvearrowleft} / \text { C } \quad \mathbf{y} \text { llyfr 'the book' o'r llyfr 'from the book' }
\end{aligned}
$$

A context that reveals more about the nature of these different types of ghosts are combinations of appearing and disappearing ghosts. As can be seen in (9), the appearing ghost $/ \mathbf{g}_{\mathscr{\Omega}} /$ remains unrealized and only the disappearing ghost $/ \mathbf{r}_{\mathfrak{A}} /$ surfaces. This is especially unexpected in (9-b) where an additional coda is created although we saw that ghosts are not realized to avoid additional codas (8-b). In addition, in an alternative imaginable surface form *gydag y nod, no ghost creates an additional marked coda or vowel hiatus.

(9) Combination of adjacent appearing and disappearing ghosts (Hannahs \& Tallerman, 2006:784+785)
a. /gydag $\mathbf{g}_{\cap} \mathbf{y}_{\curvearrowleft} \mathbf{r}_{\curvearrowleft}$ offer/
gyda'r offer 'with the equipment'
b. $/$ gydag $\mathbf{g}_{\cap} \mathbf{y}_{\curvearrowleft} \mathbf{r}_{\curvearrowleft}$ nod/
gyda'r nod 'with the aim'

This challenging pattern of interacting ghosts within one form is one of the reasons why Hannahs \& Tallerman (2006) reject a phonological account of the definite allomorphy that derives all its surface appearances from a single underlying form. ${ }^{7}$ In contrast, it is shown in 3.2 that this pattern straightforwardly follows in an account based on Gradient Symbolic Representations that can implement that 1) $/ \mathbf{y}_{\triangle} \mathbf{r}_{\Omega} /$ are disappearing

5 I follow Hannahs \& Tallerman (2006) in using the Welsh orthography: /yr/=[ər], /y/=[ə], and /'r/=[r].

6 The detailed account of the pattern in Hannahs \& Tallerman (2006) involves more facts that are not addressed here for reasons of space. An example is the unexpected choice of /y/ over unstressable /'r/ in case the definite article is focussed and thus stressed (p.791). Such an additional phonological condition seems compatible with the present account.

7 Another reason is the interaction with soft mutation (e.g. Hannahs, 1996; Green, 2006) that affects, for example, the initial consonant of feminine singular nouns after the definite article. Since it changes some underlyingly C-initial nouns into V-initial ones, it affects the allomorphy of the definite article. As Hannahs \& Tallerman (2006) put it: 'lenition on the noun $[\ldots]$ is triggered when the noun follows the article, but the correct form of the article [...] can't be inserted unless the initial segment of the noun is known, which depends on whether or not lenition has applied' (p.785). An account of this interesting interaction is unfortunately beyond the scope of the paper but is seemingly unproblematic in a model where the mutation and the surface form of the article are determined in parallel in the phonology. 
ghosts whose default state is to be there whereas $/ \mathbf{g}_{囚} /$ is an appearing ghost whose default state is to not be there, and 2) different ghosts can have different thresholds for resolving markedness. More concretely, the appearing ghost $/ \mathbf{g}_{\Omega} /$ only surfaces if it can avoid a vowel hiatus. In contrast, the realization of $/ \mathbf{y}_{\AA} /$ and $/ \mathbf{r}_{\Omega} /$ is restricted by both the demand to avoid codas and vowel hiatus. That not both of them can be deleted in (9) is due to a restriction that some portion of the definite morpheme needs to surface.

2.3 Ghosts only contribute gradiently to markedness in Ahousaht Nuu-chah-nulth The discussion so far concentrated on how markedness constraints are avoided via (non)realization of ghosts. Another interesting property of ghosts with respect to markedness is that they are sometimes not as bad a markedness problem as non-ghosts. This is illustrated with data from Ahousaht Nuu-chah-nulth (Kim, 2003) in (10). Recall that some suffixes in the language begin with consonants that only surface post-vocalically (10-i), never post-consonantally (10-ii). They can thus be classified as disappearing ghosts whose non-realization avoids either a coda for $/-\mathbf{C}_{\AA} \mathrm{V} /$-suffixes ((10-a-ii): *t'is.qum 4$)$ or a complex coda for $/-\mathbf{C}_{\AA} \mathrm{CV} /$-suffixes ((10-b-ii): ${ }^{*} k^{w} i s k$. جa:). Both structures are possible outside the context of ghost consonants in the language.

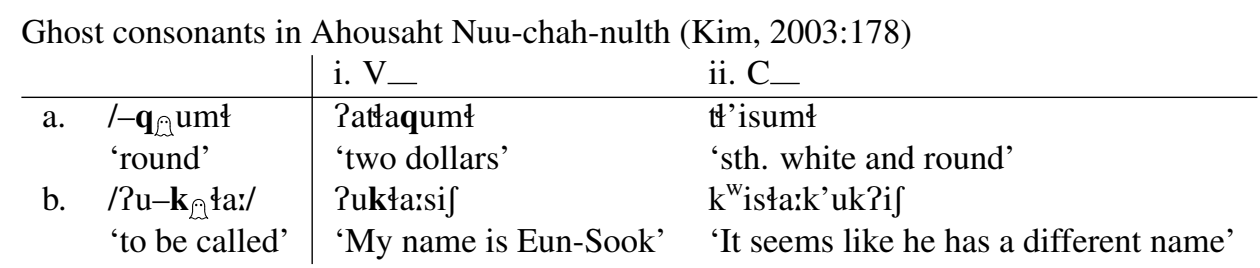

Though the empirical generalization seems uncomplicated, the data poses a serious challenge for theoretical accounts since ghosts within one language disappear to avoid different marked structures. And crucially, ghosts appear in contexts that create exactly the marked structure that other ghosts avoid. More concretely all suffixes with a $/-\mathbf{C}_{\widehat{\Omega}} \mathrm{CV} /$ shape create a coda consonant if their ghost is realized after a vowel (10-b-i). Paradoxically however, new codas are exactly what is avoided by the non-realization of ghosts in suffixes of the shape $/-\mathbf{C}_{\Omega} \mathrm{V} /(10-\mathrm{a}-\mathrm{ii})$. The conundrum is thus why (10-b-i) does not surface as *?uła:sif with deletion of the ghost. The theoretical account in 3.3 is based on the important observation that in these two contexts, the new codas are different: a non-ghost in the coda is avoided in (10-a-ii) but a ghost in the coda is tolerated in (10-b-i). The assumption of Gradient Symbolic Representations straightforwardly allows to capture this distinction in the phonology: since ghosts are weak, they are weaker problems for markedness constraints.

\section{Account: Ghosts are Weak}

3.1 Background: Gradient Symbolic Representations The assumption of Gradient Symbolic Representations (=GSR) states that phonological elements can have different degrees of presence in an underlying representation, expressed as numerical activities (Smolensky \& Goldrick, 2016; Rosen, 2016). In the original proposal, this claim is part of a larger research program where GSR are the data for Gradient Symbolic Computation, a computational architecture for cognition. For the phonology, the important prediction is that elements with different activities can behave differently in the phonology since they violate constraints to different degrees. GSR thus has the potential for being a general representational account of exceptional phonological behaviour where certain morphemes behave unexpectedly given the general phonology of the language (Smolensky \& Goldrick, 2016; Rosen, 2016; Kushnir, 2019; Zimmermann, 2018, to appear). The crucial mechanism for different phonological behaviour that depends on underlying activity are gradient constraint violations. More concretely, the faithfulness constraints MAX and DEP in GSR penalize any change of activity for an element $(11-\mathrm{a}+\mathrm{b})^{8}$; they are hence gradiently violable. An assumption that departs from the original GSR proposal in Smolensky \& Goldrick (2016) and Rosen (2016) is that elements can also be weakly active in the output (Zimmermann, 2018). The crucial consequence is that this allows gradient violations of markedness constraints as can be seen in the gradient definition of $* C C]$ in (11-c). ${ }^{9}$ This concept will be essential in the account of Ahousaht Nuu-chah-nulth that is based on gradient markedness.

\footnotetext{
8 In the original proposal, MAX is a rewarding constraint (Smolensky \& Goldrick, 2016; Rosen, 2016). All the arguments that follow are compatible with either a penalizing or rewarding version of $\mathrm{MAX}_{\mathrm{S}}$.

9 The definition in (10) refers to 'mean activity' and hence sums up the activity of all elements that form the marked structure and divides this by the number of elements.
} 
That output elements are ideally fully active is in this model ensured by a violable constraint (11-d).

a. MAX $_{S}$ : Assign violation $\mathrm{X}$ for any segmental activity $\mathrm{X}$ in the input that is not present in the output.

b. DEPS: Assign violation $\mathrm{X}$ for any segmental activity $\mathrm{X}$ in the output that is not present in the input.

c. $* \mathrm{CC}]$ : Assign violation $\mathrm{X}$ for every pair of adjacent consonants in a coda position that have the mean activity $\mathrm{X}$.

d. FULL!: Assign violation 1-X for every output element with activity X.

Another important background assumption is that the harmony evaluation is based on Harmonic Grammar where constraints are weighted, not ranked (Legendre et al., 1990; Potts et al., 2010). ${ }^{10}$ The toy example (12) illustrates gradient constraint violations and their consequences for the phonological behaviour of elements with different activities. The input contains three fully active segments /bat/ (=subscript 1) and one weakly active segment $/ \mathrm{p} /$ that only has an underlying activity of 0.5 . Three important consequences arise for this weakly active segment: for one, its realization is costly since if it involves either a weakly active segment in the output and thus violates FULL! (12-a) or insertion of activity under violation of DEPS (12-b). Secondly, its deletion is cheaper than the deletion of a fully active segment: whereas the latter incurs a MAX violation of -1 (12-c), the former only induces -0.5 violations (12-d). And thirdly, if the weak segment creates a structure penalized by a markedness constraint $\mathrm{M}$, only a gradient violation of $\mathrm{M}$ arises (12-a).

Toy example: Gradient Activity=gradient constraint violations

\begin{tabular}{|cc||c|c|c|c||c|}
\hline $\mathrm{b}_{1} \mathrm{a}_{1} \mathrm{t}_{1}-\mathrm{p}_{0.5}$ & $\begin{array}{c}\text { FULL } \\
10\end{array}$ & $\begin{array}{c}\text { MAX } \\
10\end{array}$ & $\begin{array}{c}\text { DEPS } \\
10\end{array}$ & $\begin{array}{c}* \mathrm{CC}] \\
10\end{array}$ & \\
\hline \hline $\mathrm{a}$. & $\mathrm{b}_{1} \mathrm{a}_{1} \mathrm{t}_{1} \mathrm{p}_{0.5}$ & -0.5 & & & -0.75 & -12.5 \\
\hline $\mathrm{b} . \quad \mathrm{b}_{1} \mathrm{a}_{1} \mathrm{t}_{1} \mathrm{p}_{1}$ & & & -0.5 & -1 & -15 \\
\hline c. & $\mathrm{b}_{1} \mathrm{a}_{1} \mathrm{p}_{0.5}$ & -0.5 & -1 & & & -15 \\
\hline $\mathrm{d}$ & $\mathrm{b}_{1} \mathrm{a}_{1} \mathrm{t}_{1}$ & & -0.5 & & & -5 \\
\hline
\end{tabular}

Analysing ghosts as underlyingly weakly active segments predicts their main properties: first, they are part of the underlying representation of certain morphemes which predicts their idiosyncratic qualities and that their presence is bound to certain lexical contexts. Second, they are less protected by MAX and are easier to delete which explains that they only surface in certain contexts. And third, they can gradiently contribute to markedness. To illustrate the interaction between the (non)realization of weakly active segments and violations of markedness constraints, the crucial weighting arguments for appearing and disappearing ghosts are given in (13) and (14) with abstract examples. The activation of the ghost segment is abbreviated with ' $\mathrm{A}$ ' that stands for some number lower than the full activity 1 . FULL! is taken to be so high-weighted that no relevant candidates violate it: all output elements are thus fully active. Recall that for an appearing ghost, the default state is to not be realized. The harmony score resulting from strengthening it to an output segment is hence worse than the one resulting from deleting it (13-i). If the presence of an appearing ghost can avoid a markedness violation, however, this will override its preference for not being there and the ghost is realized (13-ii). Formally, this is a gang effect in HG (Farris-Trimble, 2008; Pater, 2016): though the DEPs violations of the ghost result in a worse harmony score than its $\mathrm{MAX}_{\mathrm{S}}$ violations (13-iv-a), the combined violations of $\mathrm{MAX}_{\mathrm{S}}$ and a markedness constraint ' $\mathrm{M}$ ' are worse than the DEPS violations (13-iv-b). At this point it hence becomes crucial that the model is based on weighted constraints, not a strict ranking. Finally, true epenthesis never applies to avoid the same markedness constraint violation (13-iii). It is hence crucial that ' $A$ ' in (13) abbreviates some activity lower than 1: insertion of the missing activity is cheaper than inserting a new segment. For a disappearing ghost, the weighting arguments are basically reversed (14-iv): its default state is to be there and insertion of the missing activity is hence less costly than deleting the ghost (14-i). If its presence creates some additional markedness violation, however, it is not realized (14-ii). This deletion is in contrast to non-ghosts that are not deleted (14-iii). Again, the activity ' $\mathcal{A}$ ' is crucially lower than 1 and deletion of the ghost is cheaper than deletion of a fully active segment.

\footnotetext{
${ }^{10}$ It has to be noted, though, that the assumption of gradient activation and of HG are in principle orthogonal.
} 
Appearing ghosts in GSR

i. Default: Absence

\begin{tabular}{|c|c|c|c|}
\hline $\operatorname{VCV}_{\AA}$ & M & $\operatorname{MAX}_{\mathrm{S}}$ & DEPS $_{S}$ \\
\hline a. $\mathrm{VCV}$ & & & $-(1-\cap)$ \\
\hline b. $\quad \mathrm{VC}$ & & $-\rho$ & \\
\hline
\end{tabular}

ii. Appears if markedness is avoided

\begin{tabular}{|c|c|c|c|c|}
\hline \multicolumn{2}{|c|}{$\overline{V C C V}_{\text {周 }}$} & $\mathrm{M}$ & $\overline{\text { MAX }_{S}}$ & DEPS $_{S}$ \\
\hline$a$. & VCCV & & & $-(1-\cap)$ \\
\hline b. & VCC & -1 & - & \\
\hline
\end{tabular}

iii. No regular epenthesis

\begin{tabular}{|rl||c|c|c|}
\hline \multicolumn{2}{|c||}{ VCC } & M & MAX $_{S}$ & DEPS $_{S}$ \\
\hline \hline a. & VCCV & & & -1 \\
\hline b. & VCC & -1 & & \\
\hline
\end{tabular}

iv. Weighting arguments
a. (1- $\sim) \times$ DEPS $_{S} \gg \sim \mathrm{MAX}_{\mathrm{S}}$
b. $\quad \mathrm{M}+\mathcal{\sim} \sim \mathrm{MAX}_{\mathrm{S}} \gg(1-\mathcal{\sim}) \times \mathrm{DEP}_{\mathrm{S}}$
c. DEPS $\gg \mathrm{M}$

Disappearing ghosts in GSR

i. Default: Presence

\begin{tabular}{|rl||c|c|c|}
\hline \multicolumn{2}{|c||}{ VCV $_{\text {ค }}$} & $\mathrm{M}$ & MAX $_{\mathrm{S}}$ & DEP $_{\mathrm{S}}$ \\
\hline \hline a. & VCV & & & $-(1-\mathcal{\Omega})$ \\
\hline b. & VC & & $-\cap$ & \\
\hline
\end{tabular}

ii. Disappears if markedness is avoided

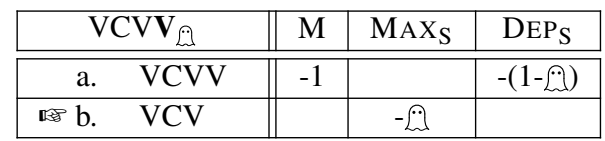

iii. No regular deletion

\begin{tabular}{|rl||c|c|c|}
\hline \multicolumn{2}{|c||}{ VCVV } & M & MAX $_{S}$ & DEPS $^{2}$ \\
\hline \hline a. & VCVV & -1 & & \\
\hline b. & VCV & & -1 & \\
\hline
\end{tabular}

iv. Weighting arguments

$$
\begin{aligned}
& \text { a. } \sim \mathrm{x}_{\mathrm{MAX}} \gg(1-\AA) \mathrm{x} \mathrm{DEP}_{\mathrm{S}} \\
& \text { b. } \quad M+(1-\cap) \times \operatorname{DEP}_{S} \gg \Omega \times \operatorname{MAX}_{S} \\
& \text { c. } \mathrm{MAX}_{\mathrm{S}} \gg \mathrm{M}
\end{aligned}
$$

3.2 A GSR account of Welsh Given the general GSR account of appearing and disappearing ghosts in (13) and (14), an analysis for Welsh needs to show that (13-iv) and (14-iv) can be true for different ghosts within one language. Since they thus have to co-exist under a single constraint weighting, the crucial key to such an account is a distinction into ghosts that are weak to different degrees. The representational assumptions for ghosts in Welsh are given in (15): the appearing ghosts at the end of certain words have an underlying activity of 0.2 and the definite article contains two disappearing ghosts with an activity of 0.6.

Two types of ghosts in Welsh
a. Appearing ghosts: $/ \mathrm{g}_{1} \mathrm{u}_{1} \mathrm{~d}_{1} \mathrm{a}_{1} \mathbf{g}_{0.2} /$
b. Disappearing ghosts: $/ \mathbf{y}_{\mathbf{0 . 6}} \mathbf{r}_{\mathbf{0 . 6}} /$

The gradient violations of DEPS and MAX $\mathrm{X}_{\mathrm{S}}$ for these different segment then predict their different default states and their different thresholds to avoid different markedness constraints. The relevant markedness constraints that determine the (non)realization of ghosts in Welsh are *COD and *HIAT (16).

a. *COD: Assign violation $\mathrm{X}$ for every coda consonant with activity $\mathrm{X}$.

b. *HIAT: Assign violation $\mathrm{X}$ for every pair of adjacent vowels that have the mean activity $\mathrm{X}$.

Again, FULL! is taken to have a very high weight in Welsh and no candidates with weak activity in the output are considered in the following. The interaction of gradient $\mathrm{MAX}_{\mathrm{S}}$ and $\mathrm{DEP}_{\mathrm{S}}$ violations and (16) predicts that $/ \mathbf{y}_{0.6} /$ and $/ \mathbf{r}_{0.6} /$ are realized unless their realization would create a $*$ COD or $*$ HIAT violation, whereas $/ \mathbf{g}_{0.2} /$ is not realized unless it can avoid a *HIAT violation. The relevant weighting arguments are illustrated below with exemplifying weights for the relative weight differences. The first tableau in (17) shows that neither of the markedness constraints triggers insertion or deletion in Welsh outside of ghost segment contexts.

\begin{tabular}{|c|c|c|c|c|c|}
\hline$\ldots \mathrm{V}_{1} \mathrm{a}_{1} \mathrm{f}_{1} \mathrm{o}_{1} \mathrm{n}_{1} \mathrm{C}_{1} \mathrm{~V}_{1} \ldots$ & $\begin{array}{c}\text { MAX }_{\text {S }} \\
10\end{array}$ & $\begin{array}{c}\text { DEPS } \\
10\end{array}$ & $\begin{array}{c}\text { *HIAT } \\
7\end{array}$ & $\begin{array}{c}* \mathrm{COD} \\
5\end{array}$ & \\
\hline a. $\quad \mathrm{V}_{1} \cdot \mathrm{a}_{1} \cdot \mathrm{f}_{1} \mathrm{o}_{1} \mathrm{n}_{1} \cdot \mathrm{C}_{1} \mathrm{~V}_{1}$ & & & -1 & -1 & -12 \\
\hline b. $\quad \mathrm{V}_{1} \cdot \mathrm{f}_{1} \mathrm{O}_{1} \cdot \mathrm{C}_{1} \mathrm{~V}_{1}$ & -2 & & & & -20 \\
\hline c. $\quad \mathrm{V}_{1} \cdot \mathrm{P}_{1} \mathrm{a}_{1} \cdot \mathrm{f}_{1} \mathrm{o}_{1} \mathrm{n}_{1} \partial_{1} \cdot \mathrm{C}_{1} \mathrm{~V}_{1}$ & & -2 & & & -20 \\
\hline
\end{tabular}

No insertion or deletion outside of ghost segment contexts

Since MAX $_{S}$ has a higher weight than *COD and *HIAT, there is never deletion to avoid a coda or a vowel hiatus (17-b) and since DEPS also has a higher weight than both *COD and *HIAT, no epenthetic segment is 
inserted to avoid these two marked structures (17-c). For all following tableaux, the most relevant weighting arguments (=WA's) established are given below the tableau. Tableaux (18) and (19) show the different default states for the ghosts in Welsh. Recall that if the ghosts surface, they have to be neutralized to fully active segments under violation of DEPs. For illustrating purposes, MAX and DEPS have an identical weight in the exemplifying tableaux to illustrate the importance of gradient constraint violations resulting from gradient activity. Consequently, ghosts with an activity lower than 0.5 are not realized in their default state (18). Ghosts with an activity higher than 0.5 , on the other hand, are realized (19). The two straightforward weighting arguments mirroring (13) and (14) are given in (18-WA) and (19-WA).

$/ \mathrm{g}_{0.2} /$ is more absent than present

\begin{tabular}{|r||c|c||c|}
\hline $\mathrm{g}_{1} \mathrm{u}_{1} \mathrm{~d}_{1} \mathrm{a}_{1} \mathbf{g}_{\mathbf{0 . 2}}$ & $\begin{array}{c}\text { MAX } \\
10\end{array}$ & $\begin{array}{c}\text { DEPS } \\
10\end{array}$ & \\
\hline \hline a. $\quad \mathrm{g}_{1} \mathrm{u}_{1} \mathrm{~d}_{1} \mathrm{a}_{1} \mathbf{g}_{\mathbf{1}}$ & & -0.8 & -8 \\
\hline b. $\quad \mathrm{g}_{1} \mathrm{u}_{1} \mathrm{~d}_{1} \mathrm{a}_{1}$ & -0.2 & & -2 \\
\hline
\end{tabular}

WA: $0.8 \times$ DEP $_{S} \gg 0.2 \times$ MAX $_{S}$
(19)

$/ \mathrm{y}_{0.6} \mathrm{r}_{0.6} /$ is more present than absent

\begin{tabular}{|c|c|c|c|}
\hline $\mathbf{y}_{0.6} \mathbf{r}_{0.6}$ & $\begin{array}{c}\text { MAX }_{S} \\
10 \\
\end{array}$ & $\begin{array}{c}\text { DEPS }_{S} \\
10 \\
\end{array}$ & \\
\hline $\begin{array}{ll}\mathbf{y}_{1} \mathbf{r}_{1} \\
\text { a. }\end{array}$ & & -0.8 & -8 \\
\hline b. & -1.2 & & -12 \\
\hline
\end{tabular}

WA: $0.6 \times \mathrm{MAX}_{\mathrm{S}} \gg 0.4 \times \mathrm{DEP}_{\mathrm{S}}$

The appearing nature of ghosts with activity 0.2 is shown in (20): as in (13), they leave their default state and are realized if they can avoid a markedness violation, in this case of *HIAT. The harmony score resulting from a *HIAT violation and $0.2 \mathrm{xMAX}_{\mathrm{S}}$ violations combined $(20-\mathrm{b})$ are enough to override the $0.8 \mathrm{xDEP} \mathrm{S}$ violations that result from realizing the ghost (20-a). In all contexts where no vowel hiatus is avoided by realizing the $/ \mathrm{g}_{0.2} /$, it will not be realized due to the weighting argument (18-WA).

Appearing $/ \mathrm{g}_{0.2} /:$ Realized to avoid a hiatus

\begin{tabular}{|r||c|c|c|c||c|}
\hline $\mathrm{g}_{1} \mathrm{u}_{1} \mathrm{~d}_{1} \mathrm{a}_{1} \mathbf{g}_{\mathbf{0 . 2}} \mathrm{V}_{1} \ldots$ & $\begin{array}{c}\text { MAX }_{\mathrm{S}} \\
10\end{array}$ & $\begin{array}{c}\text { DEP } \\
10\end{array}$ & $\begin{array}{c}\text { *HIAT } \\
7\end{array}$ & $\begin{array}{c}* \text { COD } \\
5\end{array}$ & \\
\hline \hline a. $\quad \mathrm{g}_{1} \mathrm{u}_{1} \cdot \mathrm{d}_{1} \mathrm{a}_{1} \cdot \mathrm{g}_{\mathbf{0 . 2}} \mathrm{V}_{1}$ & & -0.8 & & & -8 \\
\hline b. $\quad \mathrm{g}_{1} \mathrm{u}_{1} \cdot \mathrm{d}_{1} \mathrm{a}_{1} \cdot \mathrm{V}_{1}$ & -0.2 & & -1 & & -9 \\
\hline
\end{tabular}

WA: $*$ HIAT $+0.2 \times$ MAX $_{S} \gg 0.8 \times$ DEPS $_{S}$

Disappearing ghosts, on the other hand, only leave their default state if that avoids a markedness violation, parallel to (14). In contrast to the appearing ghost (20), both *COD and *HIAT will be avoided via disappearing of either $/ y_{0.6} /$ or $/ \mathrm{r}_{0.6} /$. Tableau (21) shows the first of these two repair contexts: the consonantal ghost disappears to avoid a violation of $*$ COD. The combination of $0.4 \mathrm{xDEPS}$ violations and a violation of * COD in (21-a) is already worse than the 0.6 violations of MAX in optimal (21-b). The sub-optimality of candidate (21-d) that also perfectly satisfies both *COD and *HIAT and leaves both ghosts unrealized again shows that in the absence of markedness violations, the disappearing ghosts are preferably realized (cf. (19)).

Disappearing $/ \mathrm{y}_{0.6} \mathrm{r}_{0.6} /: / \mathrm{r} /$ not realized to avoid a coda

\begin{tabular}{|c|c|c|c|c|c|}
\hline$\ldots \mathrm{V}_{1} \mathrm{C}_{1} \mathbf{y}_{\mathbf{0 . 6}} \mathbf{r}_{0.6} \mathrm{C}_{1} \mathrm{~V}_{1} \ldots$ & $\begin{array}{c}\mathrm{MAX}_{\mathrm{S}} \\
10\end{array}$ & $\begin{array}{c}\text { DEPS } \\
10\end{array}$ & $\begin{array}{c}\text { *HIAT } \\
7\end{array}$ & $\begin{array}{c}{ }^{*} \text { COD } \\
5\end{array}$ & \\
\hline $\begin{array}{ll}\text { a. } & \mathrm{V}_{1} \cdot \mathrm{C}_{1} \mathbf{y}_{1} \mathbf{r}_{1} \cdot \mathrm{C}_{1} \mathrm{~V}_{1}\end{array}$ & & 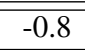 & & $\overline{-1}$ & 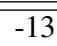 \\
\hline b. $\quad \mathrm{V}_{1} \cdot \mathrm{C}_{1} \mathbf{y}_{\mathbf{1}} \cdot \mathrm{C}_{1} \mathrm{~V}_{1}$ & -0.6 & -0.4 & & & -10 \\
\hline c. $\quad \mathrm{V}_{1} \mathrm{C}_{1} \cdot \mathrm{r}_{1} \mathrm{C}_{1} \mathrm{~V}_{1}$ & -0.6 & -0.4 & & -1 & -15 \\
\hline d. $\quad \mathrm{V}_{1} \cdot \mathrm{C}_{1} \mathrm{~V}_{1}$ & -1.2 & & & & -12 \\
\hline
\end{tabular}

WA: $* \mathrm{COD}+0.4 \times \mathrm{DEP}_{\mathrm{S}} \gg 0.6 \times \mathrm{MAX}_{\mathrm{S}}$

The interaction with the second markedness constraint is shown in (22): the vocalic ghost disappears to avoid a violation of *HIAT in optimal (22-c). Again, another gang effect of a markedness constraint and DEPs can be observed: though 0.6 violations of $\mathrm{MAX}_{\mathrm{S}}$ are in principle worse than 0.4 violations of DEPS (cf. (19)), the picture changes if an additional *HIAT violation is avoided via non-realization (22-WA). 
Disappearing $/ \mathrm{y}_{0.6} \mathrm{r}_{0.6} /: / \mathrm{y} /$ not realized to avoid a hiatus I

\begin{tabular}{|rl||c|c|c|c||c|}
\hline$\ldots \mathrm{V}_{1}$ & $\mathbf{y}_{\mathbf{0 . 6}} \mathbf{r}_{\mathbf{0 . 6}} \mathrm{V}_{1} \ldots$ & $\begin{array}{c}\text { MAX } \\
10\end{array}$ & $\begin{array}{c}\text { DEPS } \\
10\end{array}$ & $\begin{array}{c}\text { *HIAT } \\
7\end{array}$ & $\begin{array}{c}* \text { COD } \\
5\end{array}$ & \\
\hline \hline a. & $\mathrm{V}_{1} \cdot \mathbf{y}_{\mathbf{1}} \cdot \mathbf{r}_{\mathbf{1}} \mathrm{V}_{1}$ & & -0.8 & -1 & & -15 \\
\hline b. & $\mathrm{V}_{1} \cdot \mathbf{y}_{\mathbf{1}} \cdot \mathrm{V}_{1}$ & -0.6 & -0.4 & -2 & & -24 \\
\hline c. & $\mathrm{V}_{1} \cdot{ }^{\prime} \mathbf{r}_{\mathbf{1}} \mathrm{V}_{1}$ & -0.6 & -0.4 & & & -10 \\
\hline d. & $\mathrm{V}_{1} \cdot \mathrm{V}_{1}$ & -1.2 & & -1 & & -19 \\
\hline
\end{tabular}

WA: $*$ HIAT $+0.4 \times$ DEPS $_{S} \gg 0.6 \times$ MAX $_{S}$

The realization of $/ \mathbf{y}_{\bigcap} \mathbf{r}_{\Omega} /$ involves an additional complication that relates to the competing contexts for their realization, repeated in (23). In a context where the combination of preceding and following segments makes it impossible to avoid both a *COD and a *HIAT violation (23-c), satisfaction of *HIAT is more important and the consonantal ghost survives though this implies a violation of *COD.

Disappearing ghosts in the Welsh: Competing contexts
a. $\quad / \mathbf{y}_{\curvearrowleft} \mathbf{r}_{\AA} /-\mathrm{V}$ yr afon 'the river'
b. $\quad / \mathbf{y}_{\AA} \mathbf{r}_{\AA} / \ldots \mathrm{C}$ y llyfr 'the book'
c. $/ \mathbf{y}_{\curvearrowleft} \mathbf{r}_{\curvearrowright} / \mathrm{V}_{-}$
o'r afon 'from the river'
o'r llyfr 'from the book'

This crucially means that not realizing both ghosts of the definite article at the same time is excluded. Which is a natural restriction given that these two segments are the only exponents for the morpheme. The GSR account ensures this with the inclusion of REALIZEMORPHEME (van Oostendorp, 2007) demanding that every morpheme is realized via some phonological exponent (24).

RM: Assign -1 violation for every morpheme that is present in the input but no output element is affiliated with this morpheme.

Tableau (25) optimizes the relevant context where the high weight of RM forces at least one of the two ghosts to be realized and excludes the candidate that avoids all markedness violations (25-d). The weightings of the markedness constraints now determine which marked structure is the tolerable one. Given that *HIAT has a higher weight than ${ }^{*} \mathrm{COD}$, the consonantal ghost $/ \mathrm{r}_{0.6} /(25-\mathrm{c})$ will be chosen over the vocalic ghost $/ \mathrm{y}_{0.6} /$ (25-b) in every case where a violation of one of these markedness constraint is unavoidable.

Disappearing $/ \mathrm{y}_{0.6} \mathrm{r}_{0.6} /:$ / $/$ not realized to avoid a hiatus II

\begin{tabular}{|rl||c|c|c|c|c||c|}
\hline$\ldots \mathrm{V}_{1}$ & $\mathbf{y}_{\mathbf{0 . 6}} \mathbf{r}_{\mathbf{0 . 6}} \mathrm{C}_{1} \mathrm{~V}_{1} \ldots$ & $\mathrm{RM}$ & $\mathrm{MAX}_{\mathrm{S}}$ & DEPS & $*$ HIAT & $*$ COD & \\
& & 100 & 10 & 10 & 7 & 5 & \\
\hline \hline a. & $\mathrm{V}_{1} \cdot \mathbf{y}_{1} \mathbf{r}_{1} \cdot \mathrm{C}_{1} \mathrm{~V}_{1}$ & & & -0.8 & -1 & -1 & -20 \\
\hline b. & $\mathrm{V}_{1} \cdot \mathbf{y}_{1} \cdot \mathrm{C}_{1} \mathrm{~V}_{1}$ & & -0.6 & -0.4 & -1 & & -17 \\
\hline c. & $\mathrm{V}_{1} \mathbf{r}_{1} \cdot \mathrm{C}_{1} \mathrm{~V}_{1}$ & & -0.6 & -0.4 & & -1 & -15 \\
\hline d. & $\mathrm{V}_{1} \cdot \mathrm{C}_{1} \mathrm{~V}_{1}$ & -1 & -1.2 & & & & -112 \\
\hline
\end{tabular}

WA: *HIAT $\gg *$ COD

The weighting arguments established so far will already predict the correct outcome for contexts where appearing and disappearing ghosts co-occur (26). The optimal candidate (26-c) realizes only the disappearing consonantal ghost $/ \mathrm{r}_{0.6} /$ and deletes both $/ \mathrm{g}_{0.2} /$ and $/ \mathrm{y}_{0.6} /$. Especially interesting is candidate (26-d) that realizes the other two ghosts and in fact avoids all markedness violations, even the one *COD violation of optimal (26-c). That this candidate is excluded follows from the properties of the appearing ghost $/ \mathrm{g}_{0.2} /$ that only appears to avoid a violation of *HIAT (cf. (20)). Crucially, 0.8 violations of DEPS do not outweigh one violation of $*$ COD. The two types of ghosts in Welsh hence have not only different default states as being either appearing or disappearing, they also have different markedness thresholds: whereas the disappearing ghosts happily help out to avoid either *HIAT (cf. (22)+(25)) or *CoD violations (cf. (21)), the appearing ghosts only help solving *HIAT problems (cf. (20)), *COD is too low-weighted to influence their (non)appearance. Finally, candidate (26-a) that shares the one violation of * COD with the winning candidate again illustrates the different default states: if markedness is not decisive, $/ \mathrm{g}_{0.2} /$ is absent as in (26-c). 
Combination of appearing and disappearing ghosts

\begin{tabular}{|c|c|c|c|c|c|c|}
\hline $\mathrm{g}_{1} \mathrm{u}_{1} \mathrm{~d}_{1} \mathrm{a}_{1} \mathbf{g}_{\mathbf{0 . 2}} \mathbf{y}_{\mathbf{0 . 6}} \mathbf{r}_{\mathbf{0 . 6}} \mathrm{C}_{1} \mathrm{~V}_{1} \ldots$ & $\begin{array}{l}\text { RM } \\
100\end{array}$ & $\begin{array}{c}\mathrm{MAX}_{\mathrm{S}} \\
10\end{array}$ & $\begin{array}{c}\mathrm{DEP}_{\mathrm{S}} \\
10\end{array}$ & $\begin{array}{c}\text { *HIAT } \\
7\end{array}$ & $\begin{array}{c}\text { *COD } \\
5\end{array}$ & \\
\hline a. $\quad \mathrm{g}_{1} \mathrm{u}_{\cdot 1} \mathrm{~d}_{1} \mathrm{a}_{1} \cdot \mathrm{g}_{1} \mathbf{y}_{1} \mathbf{r}_{1} \cdot \mathrm{C}_{1} \mathrm{~V}_{1}$ & & & -1.6 & & -1 & -21 \\
\hline b. $\quad \mathrm{g}_{1} \mathrm{u}_{\cdot 1} \mathrm{~d}_{1} \mathrm{a}_{1} \cdot \mathbf{y}_{1} \mathbf{r}_{1} \cdot \mathrm{C}_{1} \mathrm{~V}_{1}$ & & -0.2 & -0.8 & -1 & -1 & -22 \\
\hline c. $\quad \mathrm{g}_{1} \mathrm{u}_{1} \mathrm{~d}_{1} \mathrm{a}_{1}{ }^{\prime} \mathbf{r}_{1} \cdot \mathrm{C}_{1} \mathrm{~V}_{1}$ & & -0.8 & -0.4 & & -1 & -17 \\
\hline d. $\quad \mathrm{g}_{1} \mathrm{u}_{\cdot 1} \mathrm{~d}_{1} \mathrm{a}_{1} \cdot \mathrm{g}_{1} \mathbf{y}_{\mathbf{1}} \cdot \mathrm{C}_{1} \mathrm{~V}_{1}$ & & -0.6 & -1.2 & & & -18 \\
\hline
\end{tabular}

The case study of ghosts in Welsh summarized in (27) thus illustrates two important prediction of a GSR account: first, the assumption of gradient activity for underlying elements straightforwardly predicts that appearing and disappearing ghosts can co-exist within in a language. And second, different ghosts can differ in which markedness constraint they help to avoid with leaving their preferred default state.

\begin{tabular}{l|c|cc}
\multicolumn{3}{l}{ Different ghosts in Welsh: Summary } \\
& default state & \multicolumn{2}{|c}{ non-default state due to } \\
& & *COD & *HIAT \\
\hline $\mathrm{g}_{0.2}$ & not present (18) & no (26) & yes $(20)$ \\
$\mathrm{y}_{0.6}$ & present (19) & & yes $(22)+(25)$ \\
$\mathrm{r}_{0.6}$ & present (19) & yes (21) &
\end{tabular}

3.3 A GSR account of Ahousaht Nuu-chah-nulth The ghosts in Ahousaht Nuu-chah-nulth were characterized in 2.3 as disappearing ghosts that avoid a *COD (16-a) or *CC] (11-c) violation. The asymmetry that some ghosts avoid a violation of * COD and others don't was attributed to gradient markedness and the fact that marked structures formed by ghosts are less serious problems than marked structures formed by non-ghosts. This follows in a GSR account from the assumption that FULL! - in contrast to the Welsh account - has a weight that is lower than DEPS. Weak segments are thus not neutralized to fully active ones but surface as weak in the output. ${ }^{11}$ The weighting arguments for the default state of ghosts in Ahousaht Nuu-chah-nulth are hence slightly different and involve FULL! rather than DEPS (28). In principle, however, the account of the disappearing ghosts is completely parallel to the one in (14).
Weighting arguments for Ahousaht Nuu-chah-nulth
a. Default for disappearing ghosts is to be present: $\mathrm{MAX}_{\mathrm{S}} \gg 0.5 \mathrm{xFULL}$ !
b. Deletion of a ghost to avoid a $*$ COD or $* \mathrm{CC}]: 0.5 \times \mathrm{xULL} !+* \mathrm{COD} / * \mathrm{CC}] \gg 0.5 \mathrm{xMAX}_{\mathrm{S}}$
c. No deletion for non-ghosts: $\left.\mathrm{MAX}_{\mathrm{S}} \gg * \mathrm{CC}\right] / * \mathrm{COD}$

An important prediction arising from gradient activity in the output now results for the violations of $*$ COD. Crucially, if a ghost appears in a coda (29-a), it will only violate *COD by 0.5 . It hence only creates a gradiently marked structure. This gradient violation is not enough to justify non-realization of a disappearing ghost as in (29-b). A non-ghost segment in a coda, on the other hand, will induce a full violation of $*$ COD (30-a). If non-realization of a ghost can avoid this violation (30-b), it will indeed remain unrealized. The essential difference between the weighting arguments in (29) and (30) is thus the gradient violation of ${ }^{*} \mathrm{COD}^{12}$ The conundrum that ghosts of $/-\mathrm{C}_{\Omega} \mathrm{CV} /$ suffixes create the marked structure that ghosts of $/-\mathbf{C}_{\Omega} \mathrm{V} /$ suffixes avoid, can straightforwardly be implemented in GSR as an effect of gradient markedness.

$$
/-\mathbf{C}_{\Omega} \mathrm{CV} /: \mathbf{C}_{\Omega} \text { realized after a } \mathrm{V}\left(=\mathbf{C}_{\Omega} \text { is itself in coda position }\right)
$$

\begin{tabular}{|c|c|c|c|c|c|}
\hline $\mathrm{P}_{1} \mathrm{u}_{1}-\mathrm{k}_{0.5} \mathrm{~d}_{1} \mathrm{a}_{1}$ & $\begin{array}{c}\text { MAX }_{S} \\
20\end{array}$ & $\begin{array}{c}\text { FULL! } \\
12\end{array}$ & $\begin{array}{c}* \mathrm{CC}] \\
10\end{array}$ & $\begin{array}{c}* \mathrm{COD} \\
7\end{array}$ & \\
\hline$\Leftrightarrow$ a. $\quad \mathrm{P}_{1} \mathrm{u}_{1} \mathrm{k}_{0.5} \cdot \mathrm{l}_{1} \mathrm{a}_{1}$ & & -0.5 & & -0.5 & -9.5 \\
\hline b. $\quad ?_{1} u_{1} \cdot d_{1} a_{1}$ & -0.5 & & & & -10 \\
\hline
\end{tabular}

\footnotetext{
${ }^{11}$ Without any consequence for the phonetic interpretation. It is assumed that some languages like Ahousaht Nuu-chahnulth neutralize activation differences in the phonetics while others interpret them (cf. McCollum, 2018).

12 This is a simplification since $* \mathrm{CC}$ ] is of course also gradiently violated if a ghost creates a cluster (cf. (12)). The correct weighting argument $(28-b)$ is thus rather $0.5 x$ FULL $\left.!+\mathbf{0 . 7 5} \times x^{*} C\right] \gg 0.5 x_{M A X}$.
} 
WA: $0.5 \times \mathrm{MAX}_{\mathrm{S}} \gg 0.5 \mathrm{xFULL} !+0.5 \mathrm{x} * \mathrm{COD}$

I- $\mathbf{C}_{\Omega} \mathrm{V} /: \mathbf{C}_{\Theta}$ not realized after a $\mathrm{C}\left(=\mathbf{C}_{\Theta}\right.$ forces $\mathrm{C}$ into coda position)

\begin{tabular}{|c||c|c|c|c||c|}
\hline $\mathbb{H}_{1} \mathrm{i}_{1} \mathrm{~s}_{1}-\mathrm{q}_{0.5} \mathrm{u}_{1}$ & $\begin{array}{c}\text { MAX } \\
20\end{array}$ & $\begin{array}{c}\text { FULL! } \\
12\end{array}$ & $\begin{array}{c}* \mathrm{CC}] \\
10\end{array}$ & $\begin{array}{c}* \text { COD } \\
7\end{array}$ & \\
\hline a. $\quad \mathrm{H}_{1} \mathrm{i}_{1} \mathrm{~s}_{1} \cdot \mathrm{q}_{0.5} \mathrm{u}_{1}$ & & -0.5 & & $\mathbf{- 1}$ & -13 \\
\hline b. $\quad \mathrm{t}_{1} \mathrm{i}_{1} \cdot \mathrm{s}_{1} \mathrm{u}_{1}$ & -0.5 & & & & -10 \\
\hline
\end{tabular}

WA: $0.5 \times$ FULL! $+*$ COD $\gg 0.5 \times$ MAX $_{S}$

It has to be noted that the different behaviour of $/-\mathbf{C}_{\curvearrowleft} \mathrm{CV} /$ and $/-\mathbf{C}_{\curvearrowleft} \mathrm{V} /$ suffixes could also be interpreted as two different ghosts with different markedness thresholds, quite similar to the different markedness thresholds for ghosts in Welsh. The ghost in all $/-\mathbf{C}_{\AA} \mathrm{CV} /$ suffixes would then have a greater activity than the ghosts in $/-\mathbf{C}_{\curvearrowleft} \mathrm{V} /$ suffixes and only the latter would be weak enough to already help out lower-weighted $*$ CoD. The more active ghosts would only be deleted to satisfy $* \mathrm{CC}$ ]. Under this account, however, it would be a coincidence that the strength of a ghost correlates with it being part of a $/-\mathbf{C}_{\AA} \mathrm{CV} /$ or/ $-\mathbf{C}_{\AA} V /$ suffix. The account in (30) derives the same phonological behaviour from the concept of gradient markedness that is straightforwardly predicted if gradience can persist into the output (Zimmermann, 2018).

\section{Alternative accounts}

A large class of alternative accounts for ghosts is based on autosegmental defectivity and thus the assumption that ghosts lack some structure that all other segments have. As the GSR account presented here, these explanations are thus representational since they assume that the explanation for the exceptional behaviour of ghosts follows inside the regular phonology from an exceptional representation. There are many different defectivity accounts that can broadly be classified as being based on 1) segmental content without a prosodic position (e.g. Hyman, 1985; Noske, 1985; Rubach, 1986; Kenstowicz \& Rubach, 1987; Sloan, 1991; Yearley, 1995; Tranel, 1995, 1996a; Zoll, 1996), or 2) empty positional slots without melodic content (e.g. Spencer, 1986; Szypra, 1992). These accounts can easily predict the difference between appearing and disappearing ghosts identified in this paper. This is shown with the tableaux (31) and (32) that are based on a strict constraint ranking. Under the floating feature account of ghosts in Zoll (1996), the two ghosts $/ \mathbf{i}_{\Omega} /(31)$ and $/ \mathbf{h}_{\AA} /$ (32) would only consist of segmental features without a root node. The MAX $\AA_{\Omega}$ constraint demanding that those are realized would then be MAXF preserving specific features and the * $\mathrm{A}$ constraint penalizing realization of ghosts would be DEPRT that is violated by epenthetic root nodes that are necessary to turn floating features into surface segments. The tableaux use the generalized constraint versions to show the compatibility with various defectivity accounts.

Appearing ghost and defectivity

\begin{tabular}{|c|c|c|c|c|}
\hline \multicolumn{2}{|c|}{ pana/amic-mi } & $\left.{ }^{*} \mathrm{CC}\right]$ & $* \propto$ & $\operatorname{Max} \curvearrowright$ \\
\hline $\mathrm{a}$ & pa.na.mi & & $* !$ & \\
\hline$\Leftrightarrow \mathrm{b}$ & pa.nam & & & * \\
\hline$\Leftrightarrow a$ & a.mic.mi & & $*$ & \\
\hline $\mathrm{b}$ & a.micm & $* !$ & & * \\
\hline
\end{tabular}

Disappearing ghost and defectivity

\begin{tabular}{|c|c|c|c|}
\hline doso/hogo:n-h $\mathbf{h}_{\bigcap \text { nel }}$ & $* \mathrm{CC}]$ & $\operatorname{Max} \curvearrowright$ & $* \AA$ \\
\hline a. dosohnel & & & $*$ \\
\hline b. dosonel & & $* !$ & \\
\hline a. hogo:nhnel & $* !$ & & * \\
\hline b. hogo:nnel & & * & \\
\hline
\end{tabular}

All the approaches based on autosegmental defectivity have in common that they in principle only predict a binary contrast between fully and defectively specified segments; only ghosts and non-ghosts can hence be treated differently. That such a binary distinction is insufficient for co-existing different ghosts within one language as in Yawelmani or Welsh is apparent. The tableaux (31) and (32) already show this insufficiency since they derive patterns from a single language and their ranking is inherently incompatible. A possible solution is to assume different types of defectivity or underspecification. If, for example, a non-ghost segment contains minimally a segmental root node, a place specification, and a $[ \pm$ cont] specification, one type of ghost could contain only a floating [ \pm cont] feature whereas another type of ghost would contain both floating [ \pm cont] and place features. If then MAX[PLACE], MAX[CONT], and MAXRT are ranked differently with respect to their corresponding DEP constraints and the markedness constraints relevant for the (non)appearance of ghosts, complex patterns like Yawelmani or Welsh can in principle follow. 
The general problem with this account is that it predicts that the larger the number of different ghosts within a language, the smaller the possible contrasts for ghost consonants. Since 'ghost-ness' is correlated with different degrees of underspecification, not all types of ghosts can contrast for all phonological dimensions. Given that many languages have ghosts of different quality, this seems like a problematic prediction. One example is Yawelmani where the appearing ghosts (1) contrast at least $/ \mathbf{i}_{\Omega} /$ and $/ \mathbf{a}_{\Omega} /$ and the disappearing ones (2) at least $/ \mathbf{h}_{\Omega} /, / \mathbf{m}_{\Omega} /$, and $/ \mathbf{n}_{\Omega} /$. A second more specific concern is the compatibility of these assumptions with the rest of the grammar. A floating feature analysis makes it, for example, more difficult to employ 'regular' floating features that dock to other segments (Lieber, 1992; Zoll, 1996). Ahousaht Nuu-chah-nulth is already an example since the language employs floating glottal features (Stonham, 2007). And if at least parts of the complex soft mutation in Welsh can be analysed as floating features (Lieber, 1983), a floating feature account of ghosts is also challenging for Welsh.

And the Ahousaht Nuu-chah-nulth ghosts that were analysed as being based on gradient markedness in 3.3 are impossible to capture in such accounts simply because gradient markedness violations are inherently impossible without gradient representations. A simple ranking paradox hence emerges as in $(33-a+c)$.

$$
\begin{aligned}
& \text { Ranking paradox for Ahousaht Nuu-chah-nulth under a defectivity account } \\
& \text { a. } \quad \mathrm{C}_{-}-/-\mathrm{C}_{\AA} \mathrm{V} / \quad \text { Ghosts deleted to avoid }{ }^{*} \mathrm{COD} \quad * \mathrm{COD} \gg \operatorname{Max} \propto \\
& \text { b. } \left.\left.\quad \mathrm{C} \_/-\mathrm{C}_{\AA} \mathrm{CV} / \quad \text { Ghosts deleted to avoid } * \mathrm{CC}\right] \quad * \mathrm{CC}\right] \gg \operatorname{Max} \bumpeq \\
& \text { c. } \quad \mathrm{V} \_-\mathbf{C}_{\AA} \mathrm{CV} / \text { Ghosts not deleted although } * \mathrm{COD} \text { is violated } \mathrm{Max} \cap \gg * \mathrm{COD}
\end{aligned}
$$

\section{Conclusion}

The first empirical argument in this paper was based on the distinction into different types of ghost segments: they can contrast in being appearing or disappearing and they can show different markedness thresholds. Crucially, these different types can co-exist within a single language as was shown with examples from Yawelmani and Welsh. The second empirical argument was that some ghosts only gradiently contribute to markedness, a point illustrated with ghosts in Ahousaht Nuu-chah-nulth. It was shown that both coexistence of different ghosts and gradient markedness are problematic under accounts based on autosegmental defectivity. In contrast, a new account of ghost segments was proposed that is based on the assumption of GSR and thus implements the intuition that ghosts are weaker in a very direct way. Gradient constraint violations that result from gradient underlying activity then straightforwardly predict both the co-existence of different types of ghosts and gradient markedness of ghosts. Although both Yawelmani and Welsh employ only two different types of ghosts, the GSR account predicts even more contrasts between different ghosts in a language. This follows since ghosts can not only differ in being appearing or disappearing, they can also differ with respect to their markedness threshold. It is an interesting empirical question for future research how many different types of ghosts maximally co-exist within one language and whether this additional prediction is indeed borne out. In addition, this proposal strengthens the general argument for GSR in adding another empirical area where the assumption of gradient activation predicts exceptional phonological behaviour from a simple representational contrast to the growing body of case studies employing GSR (e.g. Smolensky \& Goldrick, 2016; Rosen, 2016; Kushnir, 2019; Zimmermann, 2018, to appear).

\section{References}

Archangeli, Diana (1984). Underspecification in Yawelmani Phonology and Morphology. Ph.D. thesis, MIT.

Archangeli, Diana (1991). Syllabification and prosodic templates in Yawelmani. Natural Language and Linguistic Theory 9, 231-284.

Bonet, Eulàlia, Maria-Rosa Lloret \& Joan Mascaró (2007). Allomorph selection and lexical preferences: Two case studies. Lingua 117:6, 903-927.

Farris-Trimble, Ashley W. (2008). Cumulative faithfulness effects in phonology. Ph.D. thesis, Indiana University.

Green, Antony D. (2006). The independence of phonology and morphology: The Celtic mutations. Lingua 116, 19461985.

Hannahs, Stephen J. (1996). Phonological structure and soft mutation in Welsh. Kleinhenz, Ursula (ed.), Interfaces in Phonology, Akademie Verlag, Berlin, 46-59.

Hannahs, Stephen J. (2013). The Phonology of Welsh. Oxford University Press.

Hannahs, Stephen J. \& Maggie Tallerman (2006). At the interface: selection of the Welsh definite article. Linguistics 44, 781-816. 
Hansson, Gunnar Olafur (2005). Latent segments in Yowlumne: an epiphenomenon of template satisfaction? Armoskaite, Solveiga \& James J. Thompson (eds.), Proceedings of WSCLA 10, UBCWPL, Vancouver, 109-122.

Hyman, Larry (1985). A theory of phonological weight. Foris Publications, Dordrecht.

Kenstowicz, Michael \& Jerzy Rubach (1987). The phonology of syllabic nuclei in Slovak. Language 63, $463-497$.

Kim, Eun-Sook (2003). Theoretical issues in Nuu-chah-nulth phonology and morphology (British Columbia). Ph.D. thesis, University of British Columbia.

Kushnir, Yuriy (2019). Prosodic patterns in Lithuanian morphology. Ph.D. thesis, Leipzig University.

Legendre, Geraldine, Yoshiro Miyata \& Paul Smolensky (1990). Harmonic grammar - a formal multi-level connectionist theory of linguistic well-formedness: Theoretical foundations. Proceedings of the 12th annual conference of the cognitive science society 388-395.

Lieber, Rochelle (1983). New developments in autosegmental morphology: Consonant mutation. Barlow, Michael, Daniel P. flickinger \& Michael T. Wescoat (eds.), Proceedings of the West Coast Conference on Formal Linguistics 2, Stanford Linguistics Association, Stanford, 165-175.

Lieber, Rochelle (1992). Deconstructing Morphology. University of Chicago Press, Chicago.

McCollum, Adam (2018). Gradient morphophonology: Evidence from Uyghur vowel harmony. Talk at AMP 2018, San Diego, October 06, 2018.

Newman, Stanley (1932). The Yawelmani dialect of Yokuts. International Journal of American Linguistics 7, 85-89.

Noske, Roland (1985). Syllabification and syllable changing processes in Yawelmani. van der Hulst, Harry \& Norval Smith (eds.), Advances in Nonlinear Phonology, Foris, 335-361.

van Oostendorp, Marc (2007). Derived environment effects and consistency of exponence. Blaho, Sylvia, Patrik Bye \& Martin Krämer (eds.), Freedom of Analysis?, Mouton, Berlin, 123-148.

Pater, Joe (2016). Universal grammar with weighted constraints. McCarthy, John \& Joe Pater (eds.), Harmonic Grammar and Harmonic Serialism, Equinox, Sheffield, 1-46.

Potts, Christopher, Joe Pater, Karen Jesney, Rajesh Bhatt \& Michael Becker (2010). Harmonic grammar with linear programming: From linear systems to linguistic typology. Phonology 27, 77-117.

Rosen, Eric (2016). Predicting the unpredictable: Capturing the apparent semi-regularity of rendaku voicing in Japanese through Harmonic Grammar. Clem, Emily, Virginia Dawson, Alice Shen, Amalia Horan Skilton, Geoff Bacon, Andrew Cheng \& Erik Hans Maier (eds.), Proceedings of BLS 42, Berkeley Linguistic Society, Berkeley, 235-249.

Rowicka, Grazyna (1998). On Mohawk ghost vowels: audibility vs. visibility. Proceedings of 24th Annual Meeting of the Berkeley Linguistic Society, Berkeley Linguistic Society, Berkeley, 184-194.

Rubach, Jerzy (1986). Abstract vowels in three-dimensional phonology: The yers. The Linguistic Review 5, $247-280$.

Sloan, Kelly Dawn (1991). Syllables and Templates: Evidence from Southern Sierra Miwok. Ph.D. thesis, MIT.

Smolensky, Paul \& Matthew Goldrick (2016). Gradient symbolic representations in grammar: The case of French liaison. Ms, Johns Hopkins University and Northwestern University, ROA 1286.

Spencer, Andrew (1986). A non-linear analysis of vowel-zero alternations in Polish. Journal of Linguistics 22, $249-280$.

Stonham, John (2007). Nuuchahnulth double reduplication and stratal optimality theory. Canadian Journal of Linguistics $52,105-130$.

Szypra, Jolanta (1992). Ghost segments in nonlinear phonology: Polish yers. Langage 68, 277-312.

Tranel, Bernard (1995). The representation of French final consonants and related issues. Amastae, Jon, Grant Goodall, Marianne Phinney \& Mario Montalbetti (eds.), Contemporary Research in Romance Linguistics: Papers from the XXII Linguistic Symposium on Romance Languages, John Benjamin, Amsterdam, 53-87.

Tranel, Bernard (1996a). Exceptionality in Optimality Theory and final consonants in French. Zagona, Karen (ed.), Grammatical Theory and Romance Languages: Selected papers from the 25th Linguistic Symposium on Romance Languages (LSRL XXV), Benjamins, Amsterdam, 275-291.

Tranel, Bernard (1996b). French liaison and elision revisited: a unified account within Optimality Theory. Parodi, C., C. Quicoli \& M. Saltarelli andM. L. Zubizarreta (eds.), Aspects of Romance Linguistics, Benjamins, Amsterdam, 53-78.

Yang, So-Young (2004). Latent segments in the English indefinite article. Language and Information Society 6, 68-83.

Yearley, Jennifer (1995). Jer vowels in Russian. Beckman, Jill, Laura Walsh Dickey \& Suzanne Urbanczyk (eds.), Papers in Optimality Theory, GLSA Publications, Amherst, Mass., 533-571.

Zimmermann, Eva (2018). Being exceptional is being weak: Tonal exceptions in San Miguel el Grande Mixtec. Gallagher, Gillian, Maria Gouskova \& Sora Heng Yin (eds.), Proceedings of AMP 2017, LSA, http://dx.doi.org/10.3765/amp.

Zimmermann, Eva (to appear). Gradient symbolic representations in the output: A case study from Moses Columbian Salishan stress. Proceedings of NELS 48 .

Zoll, Cheryl (1996). Parsing below the segment in a constraint-based framework. Ph.D. thesis, UC Berkeley. 